Nakanekar Amit Vishwas et al / Int. J. Res. Ayurveda Pharm. 4(5), Sep - Oct 2013

Research Article

www.ijrap.net

\title{
AN AYURVEDIC POLYHERBAL FORMULATION PDBT FOR DYSLIPIDEMIA AND PREVENTION OF CORONARY ARTERY DISEASE (CAD) IN PRE-DIABETIC INDIVIDUALS Nakanekar Amit Vishwas ${ }^{1 *}$, Kohli Kuldip Raj ${ }^{2}$ \\ ${ }^{1}$ Ph.D. Scholar, R. A. Podar Ayurvedic Medical College, Mumbai, Maharashtra, India \\ ${ }^{2}$ Director of AYUSH Maharashtra, Dean, R. A. Podar Ayurvedic Medical College, Mumbai, India
}

Received on: 31/07/13 Revised on: 29/08/13 Accepted on: 13/09/13

*Corresponding author

E-mail: amitnakanekar@gmail.com

DOI: $10.7897 / 2277-4343.04515$

Published by Moksha Publishing House. Website www.mokshaph.com

All rights reserved.

\section{ABSTRACT}

Pre-diabetes is a 'grey area' between normal and diabetes. Various studies have shown that pre-diabetic subjects who developed diabetes had higher triglyceride and cholesterol values at baseline. At the time of diagnosis of diabetes around half of the patients will show some evidence of coronary artery disease. Treating dyslipidaemia in pre diabetes condition can not only reduce the conversion rate to diabetes but also occurrence of coronary artery disease (CAD). The Purpose of present study was to see whether an Ayurvedic polyherbal formulation PDBT which contains water extracts of Guduchi (Tinospora cordifolia), Vijaysar (Pterocarpus marsupium), Gudmar (Gymnemma sylvestre), Karvellak (Momordica charantia) and Shunthi (Zinziber officinale) can reduce mild to moderate dyslipidaemia in Pre-diabetic state as compared to placebo. A double blind placebo controlled (Randomized Controlled Trial) RCT was conducted on 100 patients (50 in each group) having mean age $48.78 \pm 10.098$; for 6 months to see the effect of polyherbal formulation as compared to placebo in pre-diabetic individuals. A diagnostic criterion for pre-diabetes was set according American Diabetic Association (ADA) 2000. Cholesterol, High Density Lipoprotein (HDL), was done with Wyebenga and Pileggi's method / Bio-lab Kit. Triglycerides were estimated by enzymatic Kit method. Blood sugar level (BSL) was calculated by Glucose oxidase- peroxidase (GOD-POD) method. Low Density lipoprotein (LDL), Very Low Density Lipoprotein (VLDL) was calculated by formula. These investigations were done before treatment (BT) and after treatment (AT). Unpaired T and paired T test were applied by INSTAT 2 software as a test of significance. Mean Cholesterol before treatment and after treatment 200.04 \pm 41.6 and 172.09 \pm 42.29 , Mean HDL before treatment and after treatment $44.544 \pm 10.517$ and $47.30 \pm$ 8.35, Mean LDL 116.37 and 92.91. Triglycerides before treatment and A. T. $160.16 \pm 132.02$ in PDBT treated group. While in placebo treated group these values were increased from $170.53 \pm 32.05$ to $191.62 \pm 36.75$, for Cholesterol before treatment and after treatment. LDL increased from $92.85 \pm$ 31.19 to 99.139 for LDL. While for triglycerides values increased from $165.75 \pm 44.33$ to $211.18 \pm 46.7$.

Keywords: Dyslipidaemia, pre diabetes, PDBT, Coronary Artery Disease (CAD)

\section{INTRODUCTION}

The international rise and incidence of diabetes is staggering. The WHO predicts that the global prevalence of Diabetes will increase to 300 million by 2025 with India set to have 57 million diabetics by $2025^{1}$. Two third of Type 2 diabetic patients die of macro vascular disease. Among them three fourth are from Coronary Artery Disease. At the time of diagnosis of diabetes around half patients will show some evidence of atherosclerosis or cardiac involvement if subjected to investigation with sophisticated tools ${ }^{2}$. Prior to development of hyperglycemia and Type 2 DM individuals undergo prolong pre-diabetic phase involving impaired glucose tolerance (IGT), impaired fasting glucose (IFG), and insulin resistance ${ }^{3}$. There is no doubt that cardiovascular risk factors are elevated long before development of diabetes, as it was shown in San-Antonio study ${ }^{4}$. Subjects in this study had high BP, Higher LDL, Triglycerides, and low HDL. The 'Rancho Bernardo' subjects who subsequently developed diabetes had higher triglycerides at the baseline ${ }^{5}$. These studies confirm that dyslipidaemia when treated early in pre-diabetes state can not only reduce the conversion rate from pre-diabetes to diabetes but also it can reduce incidence of atherosclerosis and coronary artery disease. Dyslipidaemia is becoming the cause of most complicated and life threatening disorders such as coronary artery disease, Ischemia, cerebrovascular accidents, myocardial infarction, arthritis, and various other disorders like hypertension leading to multi organ damage. The statistics says that the prevalence of dyslipidaemia in the Indian population is higher in males than in females. As per statistics $38.7 \%$ were males and $23.3 \%$ were females ${ }^{6}$. There is also increase in occurrence of $\mathrm{CAD}$ in persons having high levels of cholesterol, high triglycerides and low HDL hence there is strong association between dyslipidaemia and various vascular disorders ${ }^{7}$. Hence treating early borderline dyslipidaemia is one of the key of success in preventing cardiovascular disorders and atherosclerosis. A recent paper by Gosavi et al states that lipid management reduces the cardiovascular complications in individuals with diabetes and pre diabetes. ${ }^{8}$ Ayurveda with its holistic approach does the multi targeted action. Ayurvedic herbal medicines are multi targeted and act without much adverse drug reactions. Type $2 \mathrm{DM}$ can be compared with Prameha in Ayurveda and Pre-diabetes with poorvarupavastha ( prodromal stage) of Prameha. The concept of medadhatvani mandya, ( impaired lipid metabolism) and rasa raktagat meda ( raised levels of lipids) in the pathogenesis of prameha from its poorvarupava is extensively described in Ayurveda. Hence an Ayurvedic polyherbal formulation which is safe, cost effective, having multi targeted action with holistic approach which can be effective in pre diabetes and borderline dyslipidaemia. Plants mentioned in Ayurvedic classics were selected and formulation prepared which was termed as PDBT. A cost effective multi targeted indigenous herbal formulation is always 
safer than modern chemical agents like Atorvastatin and fenofibrates for mild to moderate Dyslipidaemia. As these drugs come up with various ADR's like fibromyalgia?, weakness in muscular layer of blood vessels; also with their action specific targets neglecting the other mechanism of dyslipidaemia. Hence a polyherbal formulation is made from aqueous extracts of Guduchi (Tinospora cordifolia), Karvellak (Momordica charantia), Vijaysar (Pterocarpus marsupium), Gudmar (Gymnemma Silvestre) and Shunthi (Zinziber officinale). All these herbs are mentioned in Ayurvedic Texts for their Medoghna ( destroying fats) and Pramehgna ( antidiabetic) action. While Guduchi is also mentioned for its Rasayan ( rejunevetive and antioxidant) properties. $^{10-12}$

\section{MATERIAL AND METHODS}

Plant material Zingiber officinale (Rhizome) batch number AHZO 1156, Tinospora cordifolia (stem), batch number AHTC 1147 Momordica Charantia (fruit) batch number AHMC1128, Gymnema sylvestre (leaves) batch number AHGS 1127, Pterocarpus marsupium (bark) batch number AHPM1112 which are indigenous to India were collected from local market and identified by Dravyaguna Department of R.A. Podar Ayurved College Worli Mumbai, India. These herbs were shadow dried and sent to Amrita Herbals, Indore for Water extraction. The extraction was done with Soxhlet apparatus after pulverisation. The extract was evaporated to dryness under vacuum desiccators $(15.5 \%$ w/w). After the standardisation of extracts as per API guidelines, PDBT capsules of $500 \mathrm{mg}$ each containing equal amount of each extract were prepared. RCT- (CTRI Ref No. REF/2013/10/005824) (Ethical Clearance Number-
2314/31-03-2011. Total 114 pre-diabetic individuals with mean Age as $48.78 \pm 10.098$ were recruited for clinical trial after approval from institutional ethics committee and successful safety and efficacy in preclinical animal studies on wristar rats ${ }^{13}$. Diagnostic criteria for pre diabetes was according $\mathrm{ADA}^{14}$ (.i.e. Fasting BSL 100-125 $\mathrm{mg} / \mathrm{dl}$, GTT 140-199 mg/dl or presence of both) 2000. Cholesterol HDL ${ }^{15-17}$, were analysed with Wyebenga and Pileggi's method / Bio-lab Kit. Triglycerides by enzymatic method (Bio lab Kit) ${ }^{18,19}$ BSL by GODPOD ${ }^{20}$ method Biolab diagnostic kit and LDL,VLDL were calculated by formula ${ }^{21-23}$. Patients were divided in to two groups Group A and Group B by lottery method of randomisation. Double blind placebo controlled study was done between the two groups. Those two groups were as follows PDBT + LSM (Lifestyle management) or Placebo + LSM. LSM defines 150 minutes of walk per week. The drug was given $1 \mathrm{~g}$ (2 capsules in each dose) BD with Luke warm water as anupana morning after breakfast (Vyana Kal) and evening before dinner (Apan Kal). The placebo was given in same format, for six months. After six months repeat Lipid profile was done. During the six month study there was 14 drop out seven from each \pm group. BSL fasting and PM was done every month to watch for conversion in Diabetes mellitus (DM). Patients who became diabetic as per WHO criteria were termed as converted to DM and they were not considered for further months. Lipid profile values at the time of diagnosis of DM were considered as after treatment values. After completion of trial blinding was opened; and data was analysed with INSTAT 2 software by applying paired T and unpaired T test. Group A was PDBT while Group B was placebo. Formula for LDL estimation-

LDL Cholesterol $=$ Sr.Cholesterol- $($ Sr. Triglycerides $/ 5+$ HDL-Cholesterol $)$. Formula for VLDL was described by Friedewalt W.T. et al in 1972. VLDL= Triglyceride/5.

\section{RESULTS}

\begin{tabular}{|c|c|c|c|c|c|}
\hline Group & Total Recruited & Dropped Out & Completed trial & Converted to Type 2 DM & Not converted to DM \\
\hline PDBT (Gr.A) & 57 & 07 & 50 & 08 & 42 \\
\hline Placebo (Gr.B) & 57 & 07 & 50 & 15 & 35 \\
\hline
\end{tabular}
Relative risk =1.438 by $95 \%$ Confidence Interval: 0.7944 to 2.601 (using the approximation of Katz.) 30.46 \% Risk reduction as compared to
placebo group

\begin{tabular}{|c|c|c|c|c|}
\hline \multicolumn{5}{|c|}{ Cholesterol } \\
\hline Group & BT & AT & P value & Test of significance \\
\hline Gr A & $200.04 \pm 41.6$ & $172.09 \pm 42.29$ & $<0.0001$ Significant & Paired T \\
\hline Gr B & $170.53 \pm 32.05$ & $191.62 \pm 36.75$ & $<0.0001$ Significant & Paired T \\
\hline P value & & 0.0154 Significant & & \\
\hline Test of significance & \multicolumn{5}{|c|}{ Unpaired T } & \\
Values are expressed as mean + SD $\mathrm{N}=50$ in Group A and Group B p <0.05) BT: Before Treatment; AT: After Treatment
\end{tabular}

\begin{tabular}{|c|c|c|c|c|}
\hline \multicolumn{5}{|c|}{ HDL } \\
\hline Group & BT & AT & P value & Test of significance \\
\hline Gr A & $44.544 \pm 10.517$ & $47.30 \pm 8.35$ & 0.0274 Significant & Paired T \\
\hline Gr B & $41.98 \pm 7.22$ & $43.76 \pm 8.03$ & 0.0128 Significant & Paired T \\
\hline $\mathrm{P}$ value & & 0.0331 Significant & & \\
\hline Test of significance & & Unpaired T & & \\
\hline
\end{tabular}

Values are expressed as mean \pm SD. $\mathrm{N}=50$ in Group A and Group B p < 0.05 BT: Before Treatment; AT: After Treatment 


\begin{tabular}{|c|c|c|c|c|}
\hline \multicolumn{5}{|c|}{ Triglycerides } \\
\hline Group & BT & AT & P value & Test of significance \\
\hline Gr A & $160.16 \pm 63.829$ & $132.02 \pm 57.158$ & 0.0002 Significant & Paired T \\
\hline Gr B & $165.75 \pm 44.33$ & $211.18 \pm 46.7$ & $<0.0001$ Significant & Paired T \\
\hline P value & & $<0.0001$ Significant & & \\
\hline Test of significance & & Unpaired T & & \\
\end{tabular}

\begin{tabular}{|c|c|c|c|c|}
\hline \multicolumn{5}{|c|}{ LDL } \\
\hline Group & BT & AT & P value & Test of significance \\
\hline Group A & $116.37 \pm 39.04$ & $92.91 \pm 35.34$ & $<0.0001$ Extre. Signi & Paired T \\
\hline Group B & $92.85 \pm 31.194$ & $99.139 \pm 33.324$ & 0.4988 Not significant & Paired T \\
\hline P value & & 0.3674 Not Significant & & \\
\hline Test of significance & & Unpaired T & & \\
\hline
\end{tabular}

Values are expressed as mean \pm SD. $\mathrm{N}=50$ in Group. A and Group. B p < 0.05 BT: Before Treatment; AT: After Treatment

\begin{tabular}{|c|c|c|c|c|}
\hline \multicolumn{5}{|c|}{ VLDL } \\
\hline Group & BT & AT & P value & Test \\
\hline Group A & $28.975 \pm 13.236$ & $25.532 \pm 10.263$ & 0.0186 Significant & Paired T \\
\hline Group B & $35.565 \pm 10.357$ & $35.541 \pm 10.316$ & 0.1621 Not Significant & Paired T \\
\hline P value & & $<0.0001$ Extre Significant & & \\
\hline Test of significance & & Unpaired T & & \\
\hline
\end{tabular}

Values are expressed as mean \pm SD. $\mathrm{N}=50$ in Group. A and Group. B p < 0.05 BT: Before Treatment; AT: After Treatment

\section{DISCUSSION}

As we can see in the chart the mean cholesterol, LDL VLDL and Triglyceride levels were decreased in Group A. These values were increased in Group B. HDL levels were increased in both groups this shows that LSM can increase HDL levels but LSM+ PDBT can increase better than only LSM. Number of individuals who became diabetic was also less in PDBT treated group. Relative risk ratio suggests that there was $30.46 \%$ risk reduction in occurrence of DM as compared to placebo. Reduction in occurrence of diabetes is indicative of reduction in CAD risk ${ }^{24}$. Sushruta has said that shukradosha ( disorders of genital systems) and prameha are due to vitiation of Vyana Vayu and Apana vayu ${ }^{25}$ keeping that reference in mind medicines were given morning after breakfast and evening before dinner. According to Ayurvedic physiology Hridaya ( $\sim$ Heart) is a site of vyan vayu. ${ }^{26}$ Medicinal timing for vyan vayu is after morning breakfast while that for apan vayu is before meals. Dyspnoea on exertion is a cardinal sign of CAD which is nicely described in clinical features of Medovruddhi by vagbhat as 'Alpe api cheshtite shwasam,27. Some of the herbs from this formulation are mentioned as medopachak ${ }^{28}$; which includes guduchi and shunthi. According to Ayurveda these herbs can treat medadhatvagni mandya, rasaraktagat meda and this combination is hridya (means beneficial for heart) also. Multi factorial etiology of CAD has been recognized for long time. Multiple risk factor intervention trial (MRFIT) focused on evaluation of multi-pronged preventive strategies and control of multiple risk factors ${ }^{29}$. For the years the focus of prevention of cardiovascular diseases has been on blood pressure, lipid profile and glycaemic control $^{30}$. The ATP III guidelines emphasize that LDL and cholesterol reduction is the primary target for prevention of CAD and increase in HDL and reduction in Triglycerides are secondary targets. While 'Ranchobernaldo' subjects who were converted to diabetic had hypertriglyceridemia. PDBT contains water extract of Ayurvedic herbs which have proved hypoglycemic activity ${ }^{31}$. This study demonstrates its action on lipid profile. Hence this will act on prevention of diabetes as well as CAD; by its multitargated action. While no other adverse drug reaction were observed during the study.

\section{CONCLUSION}

An Ayurvedic poly herbal formulation PDBT can reduce dyslipidaemia in pre-diabetics. Due to this activity this can also work against early pathogenesis of CAD. This can also delay the onset of early atherosclerosis and diabetes.

\section{ACKNOWLEDGEMENT}

Authors are thankful to HOD Dravyaguna Dept. R.A. Podar Ayu. Medical college worli, Mumbai, India for his help in identification of raw materials, Dr. Sanjay Tamoli for his help in manufacturing of Capsules containing extracts, Dr. Pratima Tatke (C.U. Shah College of Pharmacy) for pre clinical animal studies and Pathology dept. R.A. Podar Ayu. Medical college, worli, Mumbai, India for their help in doing lipid profile.

\section{REFERENCES}

1. Rao Gundu HR. Global Risk assessment For Diabetes and vascular Diseases; Need for new guidelines for south Asians. Coronary Artery Disease: Risk promoters, Pathophysiology and prevention. Jaypee brothers Medical publishers New Delhi, India; 2005.

2. Practical diabetes mellitus. PG Talwalkar $4^{\text {th }}$ edition; p. 221

3. American Diabetes association. Diagnosis and classification of Diabetes Mellitus. Position statements. Diabetes care 2004; 27: S5S10. http://dx.doi.org/10.2337/diacare.27.2007.S5 PMid:14693921

4. Haffner SM et al. Cardiovascular risk in confirmed prediabetics individuals. Does the clock of CAD starts ticking before the onset of clinical diabetes? JAMA 1990; 263: 2893-8. http://dx.doi.org/ 10.1001/jama.1990.03440210043030 PMid:2338751

5. Mcphillips JB et al. Cardiovascular disease risk factors prior to diagnosis of IGT and NIDDM in a community of older adults. Am j Epidemiol 1990; 131: 443-53. PMid:2301354

6. Sawant AM, Shetty D, Mankeshwar R, Ashavaid TF. Prevalence of dyslipidemia in young adult Indian population. J Assoc Physicians India 2008; 56: 99-102. PMid: 18472509

7. P Murthy et al. A Survey for Prevalence of Coronary Artery Disease in Urban Population in Andhra Pradesh. J Assoc Physicians India 2012; 60 .

8. Gosavi A, Flaker G, Gardner D. Lipid management reduces cardiovascular complications in individuals with diabetes and pre diabetes. Prev. cardiol 2006; 9(2): 102-7quiz108-9

9. Adverse events of statin -fenofibrate versus statin monotheraphy: A meta analysis of randomized controlled trials. Gen Q et al. Curr Med Res Opin 2013; 29(3): 181-8.

10. Database of Medicinal plants used in Ayurveda published by CCRAS; p. 288-294. 
11. Bhavprakash Nighantu Madhya Khand. Chaukhambha publication. Dr Chunekar; 2004. p. 13, 269, 443, 524, 685 .

12. Anonymous, The Wealth of India, CSIR, Publication and Information Directorate, New Delhi, Vol.VIII, Raw materials; 1969. p. 302-303.

13. Nakanekar A, Waghmare P, Tatke P, Kohli KR. In-vivo Evaluation of hypoglycemic activity of an Ayurvedic polyherbal combination. IAMJ 2013; 1(3).

14. ADA. Criteria for pre-diabetics. Official ADA website.www.diabetes.org; 2000 .

15. www.baylorhealth.edu/Documents/...25_1_Jan12_BUMC_Proc.pdf By Y Cao; 2012.

16. Hisalkar PJ. Serum lipid profiles in DM. Dissertation submitted to Dept. of Biochemistry Dr. Babasaheb Ambedkar Marathwada university; 1999. p. 40-46.

17. Burstein $\mathrm{M}$ et al. Method of Cholesterol, Lipid research 11, 583, 1970. http://www.clinchem.org/content/25/4/560.full.pdf

18. Grove TH. Total cholesterol and HDL-C method, Clinical chemistry, 25560; 1997.

19. Wybwanga et al. Clinical chemistry www.clinchem.org/content/ 16/12/980.full.pdf.

20. Bucolo G, David H. Clinical chemistry, www.biolabdiagnostics. com/chemistry/PDFs/Triglycerides.pdf; 1973. p. 19, 476.

21. U Styanarayana, U Chakrapani. Biochemistry. Third Revised edition. Books and Alled Pvt Ltd; 2006. p. 767.

22. Fridewald WT et al. Estimation of the concentration of LDLcholesterol in plasma without use of the preparative ultracentrifuge Clinical chemistry 1972; 18: 499.
23. Ralph DE et al. Lipids and lipoproteins, clinical methods; p. 516, 539.

24. Sanda C. Lipid profile, Lipid profiles, tests and their significance Lab medica; 1987.

25. Ramachandran A, Snehlata C, Satyavani K. Metabolic syndrome in urban Asian Indian adults-A population study using modified ATP III criteria. Diabetes Res Clin Pract 2003; 60: 199-204. http://dx .doi.org/10.1016/S0168-8227(03)00060-3

26. Sushrut Samhita Nidansthan $1 / 20$. Commentary by Dr Ambikadatta shastri chaukhamba publication $13^{\text {th }}$ edition; p. 230.

27. Ashtang Hridaya sutrasthan 12/6. Commetry by Dr Vd Ganesh Gadre. Anmol Publication commentary; 2003. p. 55.

28. Ashang Hridayam sutrasthan 11/11. Commentary by Vd Ganesh Gadre. Anmol Publication commentary; 2003. p. 52.

29. Ashang Hridayam chikistasthan $1 / 49$. Commentary by Vd Ganesh Gadre. Anmol Publication commentary; 2003. p. 220.

30. Stamler J. Established major coronary risk Factor: historical overview in CHD epidemiology: From etiology to public health $2^{\text {nd }}$ edition Marmott M Oxford university press; 2005.

31. Foot DK, Lewis RP, Pearson TA, Bellar GA. Demographics and Cardiology 1950-2050. JACC 2000; 35(suppl B): 66-80. http://dx. doi.org/10.1016/S0735-1097(00)90033-0

\section{Cite this article as:}

Nakanekar Amit Vishwas, Kohli Kuldip Raj. An Ayurvedic polyherbal formulation PDBT for dyslipidemia and prevention of coronary artery disease (CAD) in pre-diabetic individuals. Int. J. Res. Ayurveda Pharm. 2013;4(5):701-704 http://dx.doi.org/10.7897/2277-4343.04515 